\title{
Review
}

\section{Serum markers of intrahepatic cholangiocarcinoma}

\author{
Giulia Malaguarnera ${ }^{\mathrm{a}}$, Isabella Paladina ${ }^{\mathrm{b}}$, Maria Giordano ${ }^{\mathrm{b}, *}$, Michele Malaguarnera $^{\mathrm{c}}$, \\ Gaetano Bertino $^{\mathrm{b}}$ and Massimiliano Berretta ${ }^{\mathrm{d}}$ \\ a International PhD Program in Neuropharmacology, University of Catania Medical School, Catania, Italy \\ ${ }^{\mathrm{b}}$ Department of Internal Medicine and Systemic Diseases, University of Catania, Catania, Italy \\ ${ }^{\mathrm{c}}$ Department of Biological Chemistry, Medical Chemistry and Molecular Biology, University of Catania, Catania, \\ Italy \\ ${ }^{\mathrm{d}}$ Department of Medical Oncology, National Cancer Institute, Aviano, PN, Italy
}

\begin{abstract}
Cholangiocarcinoma (CCA) is a relatively rare type of primary liver cancer that originates in the bile duct epithelium. It is an aggressive malignancy typified by unresponsiveness to chemotherapy and radiotherapy. Despite advances in radiologic techniques and laboratory diagnostic test, the diagnosis of CCA remains highly challenging. Development in molecular techniques has led to go into the possible use of serum markers in diagnosing of cholangiocarcinoma. This review summarizes the principal characteristics of serum markers of cholangiocarcinoma. The tumour markers used frequently such as Carbohydrate antigen 19-9 (CA 19-9), Carcinogenic Embryonic antigen (CEA), and Cancer Antigen 125 have shown sufficient sensitivity and specificity to detect and monitor CCA. In particular, the combination of these tumour markers seems to increase their efficiency in diagnosing of cholangiocarcinoma. New markers such as Soluble fragment of cytokeratin 19 (CYFRA 21-1) Mucins, Tumour Markers 2 pyruvate-Kinase ( $\left.\mathrm{TuM}_{2-} \mathrm{PK}\right)$ and metalloproteinase-7 (MMP-7) have been recently shown to help in the diagnosis of CCA, with in some cases a prognostic value.
\end{abstract}

Keywords: Cholangiocarcinoma, tumor markers, CA 19-9, CEA

\section{Introduction}

Cholangiocarcinoma (CCA) is a primary malignancy which originates from bile duct epithelial cells. CCA approximates 10 to $25 \%$ of all liver cancers and the incidence of this disease has increased over the last three decades $[1,2]$. The vast majority of malignant tumours of the bile ducts presents with painless obstructive symptoms, which include pale stools, dark urine and jaundice. Right upper quadrant abdominal pain,

*Corresponding author: Maria Giordano, Department of Internal Medicine and Systemic Diseases, University of Catania, Via Messina 829, 95126 Catania, Italy. Tel.: +39 095 7262008; E-mail: mariagior@hotmail.it. fever and rigors are indicative of superimposed cholangitis [3]. CCA is a slow-growing but highly metastatic tumor, which is often detected at an unresectable stage; therefore, most patients have a poor prognosis with a median survival of 6-12 months [4]. CCA is insensitive to chemotherapy, immunotherapy, radiotherapy and and curative surgical resection is currently the only effective therapy $[5,6]$. In recent decades, the incidence and the mortality from intrahepatic cholangiocarcinoma (ICC) has progressively increased, whilst being stable for extrahepatic cholangiocarcinoma [7]. The median of patients affected by ICC who do not undergo surgery is 6 months, while the 5- year survival rate for patients following complete resection being only $20-40 \%[8,9]$. 
The Liver Cancer Study Group of Japan (LCSGJ) has distinguished three macroscopic growth types for intrahepatic cholangiocarcinoma: mass-forming type, periductal-infiltrating type, and intraductal-growth type [10]. The most common form of intrahepatic cholangiocarinoma is mass-forming type, definited as a mass located in the liver parenchyma [11]. It tends to invade the hepatic parenchyma via the portal venous system and through lymphatic vessels in advanced stages [12].

Several imaging modalities are being used in the evaluation of primary hepatic masses [13] CT and MRI are both helpful but have low specificity [14].

The sensitivity of PET for the detection of massforming intra-hepatic cholangiocarcinoma of $>1 \mathrm{~cm}$ diameter has been reported as $85-95 \%$, with a sensitivity of $100 \%$ and its sensitivity and specificity for detection of nodal and distant metastatic disease is $100 \%$ and $94 \%$, respectively [15]. In problematic cases, determination of the serum markers can be helpful too.

\section{Markers}

\subsection{Carbohydrate antigen 19-9 (CA 19-9)}

The CA 19-9 is a sialylated Lewis blood group antigen targeted by the monoclonal antibody 116 NS 19-9. It was described in 1979 as a tumour associated antigen in a colorectal cancer cell line [16].

Carbohydrate antigen 19-9 (CA19-9) is an established serum marker for the diagnosis of cholangiocarcinoma, although it is reported to have a wide variation in sensitivity (50-90\%) and specificity (54-98\%) [1719 ], and is often falsely elevated in benign biliary disease and/or cholangitis, with levels falling after relief of biliary obstruction and sepsis.

One of the most important infection of intrahepatic bile ducts is primary sclerosing cholangitis.

Primary sclerosing cholangitis is the most common known predisposing condition for cholangiocarcinoma in Western countries [20]. It is a chronic cholestasis syndrome of unknown etiology characterized by fibrosing inflammatory destruction of the intra end extrahepatic bile ducts; for this reason it represents an important risk factor for ICC.

The CA 19-9 is used as a screening tool for cholangiocarcinoma in patients with primary sclerosing cholangitis (PSC). Ramage et al. [21] in a retrospective study involved 74 patients with PSC, 15 with associated cholangiocarcinoma. In that study, a value $>$
$200 \mathrm{U} / \mathrm{ml}$ had sensitivity and specificity of $60 \%$ and $90 \%$ respectively, in differentiating PSC versus PSC with CCA.

Chalasani [17] performed a case-control study involving 26 patients with PSC but no cholangiocarcinoma. A CA $19-9>100 \mathrm{U} / \mathrm{ml}$ had a sensitivity of $75 \%$ and specificity of $80 \%$ in diagnosing cholangiocarcinoma.

Several studies found that CA19-9 expression was prevalent in ICC [20]. Shen et al. analyzed 429 patients with ICC and have found elevated CA19-9 serum levels $(>37 \mathrm{U} / \mathrm{mL})$ in $57.5 \%$ of ICC patients. Further analyses showed a correlation between CA19-9 positivity and gender, age, tumor size, cirrhosis, and HBsAg expression. Logistic regression analysis indicated that expression of CA19-9 was significantly associated with cirrhosis and lymph node metastases too, in fact ICC patients with elevated CA19-9 (> $37 \mathrm{U} / \mathrm{mL})$ presented a higher incidence metastases [22].

Multiple stuides have also demonstred that elevated serum concentrations of CA19-9 is significantly related with the prognosis in patients with ICC.

However, sensitivity and specificity of CA 19-9 are $62 \%$ and $63 \%$ respectively for diagnosing of intrahepatic cholangiocarcinoma and should, therefore, only be used for further confirmation [23]. The sensitivity and specificity grows up if CA $19-9$ is used in combination with other tumor markers.

Although studies demonstrated a higher sensitivity of CA 19-9 than CEA in diagnosing cholangiocarcinoma, it was also noted that the combination of these two tumour markers increased the sensitivity and the specificity.

\subsection{Carcinogenic embryonic antigen (CEA)}

Carcinoembryonic antigen (CEA) is a glycoprotein tumour marker with the immunodeterminant present on the protein moiety of the molecule. It is used as marker of a lot of tumours such as the cancer of stomach, colon and pancreas [24,25] but serum CEA levels have been also examined in patients with cholangiocarcinoma. Immunohistochemical studies [26,27] have shown that the biliary epithelial cells are characterized by the expression of carbohydrate antigens, therefore their serum levels alteration are correlated with biliary tract diseases.

CEA could be useful for the prognosis of patients with resectable and unresectable intrahepatic cholangiocarcinoma. Li et al. [28] showed that using at the same time pre-operative serum levels of CEA, CA 19- 
9 we might obtain a better prognosis of intrahepatic cholangiocarcinoma patients.

Serum CEA levels have been examined in four studies. These studies found that a raised pre-operative CEA had no significant relationship with survival [29].

\subsection{Cancer antigen 125}

The tumour marker CA 125 can be elevated in cholangiocarcinoma. However it is no specific and can be increased in other gastrointestinal or gynaecologic malignancies or cholangiopathies [30]. Around 2000, CA 125 was identified as MUC16 and in particular as MUC16/M11 where the antibody M11 recognizes a mucin-like glycoprotein expressing the CA125 epitope [31-33]. The increment of MUC16/M11 and therefore of CA125 is correlated to poor survival in patients with intrahepatic cholangiocarcinoma mass forming type tissues, representing an independent prognostic factor of poor survival [34].

\subsection{Serum total sialic ACID}

Sialic acid (SA) presents as components of soluble and cell surface glycoconjugates in animal cells and tissues, has been shown to be involved in cell regulation and in malignant transformations [35]. Increased levels on serum total sialic acid (TSA) concentrations have been reported in various types of tumours [3638].

Several different mechanisms are assumed to underlie the elevated SA concentrations in various cancers. Increased activity of sialyltransferase, leading to an increased amount of SA on the cell surface and the spontaneous release or shedding of aberrant SA containing cell surface glycoconjugates [39], may cause excess amounts of SA penetration into the plasma.

An increased serum TSA concentration in CCA patients in some studies yielded a high sensitivity, specificity and positivity predictive value, its clinical utility for screening cancer patients is limited because of its apparent non specificity to a given disease. SA markers might serve as adjuncts when combined with other markers, in CCA screening, progression follow- up and in monitoring response to treatment [40].

\subsection{C-reactive protein $(C R P)$}

C-reactive protein belongs to the family of acutephase protein. Its concentration changes in response to injury, infection, and neoplasia. It is up-regulated by cytokines, such as interleukin- 8 and interleukin- 6 . In vitro studies have identified Il-6 to be an autocrine growth factor of cholangiocarcinoma cell lines [41, 42]. Moreover IL-6 is elevated in the serum of patients with cholangiocarcinoma and falls sharply after resection [43]. The serum level of CRP at diagnosis is identified as an independent prognostic indicator in patients with cholangiocarcinoma. CRP has been shown to be of prognostic value in many malignancies [44] found an elevated CRP to be an independent predictor of worse survival. In ICC patients the increase of CRP can be due a complicated tumour induced stricture and the development of cholangitis. In generally, increased CRP levels in malignant disease are an inflammatory response to tumour invasion [45]. If the inflammatory state is low, we have a better prognosis. Saisho et al. [46] found that a CRP $<1.0 \mathrm{mg} / \mathrm{dl}$ is a favourable prognostic factor in patients with biliary tract cancers receiving chemotherapy.

\subsection{Serum cytokeratin 19 fragment (CYFRA 21-1)}

Cytokeratins (CK) are intermediate filament which are part of the cytoskeleton of the epithelium. Previous studies identified and catalogued 20 different CK polypeptides and divided them into type I (acidic) and type II (neutral to basic) [47,48]. Normal epithelia contain characteristic CK pairs of one type I and one type II.

Serum CYFRA 21-1 is a useful marker developed to measure a soluble fragment of cytokeratin (CK) 19 in serum. CYFRA 21-1 has a high sensitivity in non small cell lung cancer and is an useful marker in the clinical monitoring during and following treatment [4951]. CYFRA 21-1 has been reported to be a prognostic factor for various cancers [52-54].

No established tumor markers, such as carcinoembryonic antigen (CEA) and carbohydrate antigen (CA) 19-9, have sufficient sensitivity and specificity to detect and monitor ICC [55-60]. Serum cytokeratin19 fragment (CYFRA 21-1), has been reported to have higher specificities than CA 19-9 for intrahepatic cholangiocarcinoma in a limited number of studies, but is not in routine use $[23,61,62]$.

The serum CYFRA21-1 concentration had high sensitivity for ICC and reflected differences in tumor burden, suggesting applicability to staging and followup [61].

In some studies CYFRA 21-1 is a useful marker not only for detecting intrahepatic cholangiocarcinoma (ICC) early but also for distinguishing ICC from hep- 
atocellular carcinoma (HCC). In fact hepatocytes contain CK 8 and 18 while bile duct cells contain CK 7 , 8,18 and 19 [63] and the cytokeratin pattern is usually maintained during malignant transformation. The CYFRA 21-1 concentrations varied according to tumour size, vascular invasion and number of tumours. The high serum CYFRA 21 concentration is associated with tumour progression and poor postoperative outcomes in patients with CCA.

\subsection{Transforming growth factor $\beta(T G F-\beta)$}

TGF- $\beta$ is a multifunctional cytokine that regulates the growth and the differentiation of several cellular types [64]. TGF- $\beta$ plays an important role in cellular matrix formation and inhibition of hepatocytes proliferation [65]. In fact it has been shown to induce cell arrest and fibrosis in hepatocytes [66,67]. Cellular apoptosis is involved in carcinogenesis induced by growth factor deficiency or positive signals related to TGF- $\beta$ and FAS system [68]. Normally TGF- $\beta$ expression is low in intrahepatic biliary cells, but, during inflammation o because of obstructive lesions of bile duct, it increases $[69,70]$. Many malignant tumours harbour defects in TGF- $\beta$ signalling and are resistant to TGF- $\beta$ mediated growth suppression. A close correlation between disruption of the TGF-signalling pathway and deregulated growth of cancer cells has been demonstrated in cancers, including biliary tract carcinoma. There are contrasted data about the cancerogenesis effect of TGF- $\beta$; its mechanism and its function remain poorly understood. Previous studies demonstrated the resistance of ICC cells to growth inhibitory effect of TGF-beta [71,72] but Shimizu et al. [73] noted TGF$\beta 1$ stimulation in ICC resulted in cellular proliferation rather than resistance to the innate mitoinhibition [73]. The study has shown that TGF- $\beta$ accelerates ICC cell proliferation by an autocrine fashion and, at the same time, stimulates the secretion of IL- 6 that seems can induce itself the proliferation of ICC cells by a functional interaction with TGF- $\beta$ [72-74].

Yasumori Sato et al. demostrated that human cholangiocarcinoma cells underwent Epithelial-Mesenchymal Transition (EMT) by TGF- $\beta 1 /$ Snail activation, which was accompanied by the activation of invasive potential. Snail, in fact, is a trascriptional regulator that, when is activated, represses the gene expression of E-cadherin. Therefore, the Snail expression significantly correlated with the lymph node metastasis and a poor survival rate of the patients. The studies were conducted in vitro and in vivo. In vivo $16 \%$ of cholangiocarcinoma cases showed marked immunoreactivity of Snail in their nuclei [75].

\subsection{Chromogranin A (CGA)}

Chromogranin A is an acidic glycoprotein contained in secretor granules of neuroendocrine cells [76]. Serum levels can be augmented in HCC and in cirrhotic patients $[77,78]$ but, generally they are increased in patients with neuroendocrine tumours such as carcinoids and endocrine pancreatic tumours [79].

In the last years pathological similarities of ICC to pancreatic carcinoma have been proposed [80,81]. In rare cases adenocarcinomas are accompanied by a neuroendocrine component positive for chromogranin A. Histologically, the adenocarcinoma is usually located at the surface of the tumor and the majority of the stromal invasion involves the neuroendocrine component. Usually, the neuroendocrine component has a low or an high grade malignacy [82].

Neuroendocrine differentiation has been shown to be of prognostic importance in several malignancies [83].

\subsection{Tumour Marker 2 pyruvate-kinase $\left(T_{U} M_{2}-P K\right)$}

A recently identified serum tumour marker, $\mathrm{TuM}_{2}$ PK has appeared to be of interest for the diagnosis of cholangiocarcinoma. The enzyme pyruvate Kinase plays a key role in the glycolitic pathway with four organ-specific isoforms: type L in the kidney; type $\mathrm{R}$ in erythrocytes; type M1 in muscles heart and brain and type M2 in lung, undifferentiated and proliferative tissues [84-87]. The isoenzyme M2 is active as a tetramer in proliferating non tumour cells [88]. It is also expressed in all cells with a high rate of nucleic acid synthesis which include all proliferating cells and tumor cells in particular. During embryogenesis there is a shift and the pyruvate kinase M2 is converted in the isoform specific for the respective tissue. Within the tumorigenesis a lot of cells assume undifferentiated state therefore respective tissue specific isoenzymes disappear and PKM2 is over-expressed [88-93]. It has been demonstrated that the amount of type $\mathrm{M}_{2}$ pyruvate kinase extracted from neoplastic tissues increases with tumour size and metastasis [94]. $\mathrm{TuM}_{2}-\mathrm{PK}$ is released from tumour cells in body fluid. It detects a metabolic state specific for cancer cells and it can be easily measured in blood, the results are highly reproducible.

$\mathrm{TuM}_{2}$-PK concentrations were found increased significantly in patients with cholangiocarcinoma. Moreover, the diagnostic performance of $\mathrm{TuM}_{2}-\mathrm{PK}$ was higher than that of CA 19-9 with a sensitivity of $84.2 \%$ and a specificity of $90 \%$ against $68.4 \%$ and $75 \%$, 
respectively of CA19-9 [95]. Another advantage of $\mathrm{TuM}_{2}$-PK is that its concentration in blood is found to be correlated with stage of tumour. $\mathrm{TuM}_{2}-\mathrm{PK}$ can be used with good sensitivity and high specificity as a valuable diagnostic marker for cholangiocarcinoma.

\subsection{Mucins}

Mucins are large protein synthesised by epithelial cells in many organs. Mucins constitute the major component of mucus [96,97]. They form a heterogeneous group of high molecular mass, polydisperse, highly glycosylated macromolecules. Mucins are $\mathrm{O}$-glycosilated proteins mainly expressed by ductal and glandular epithelial tissues. Human mucin genes are designated according to their distinct structures and functions as transmembrane mucins or secreted gel-forming mucins. Mucin genes are expressed in cells and tissues, specific manner Muc2 and Muc3 in bowel [98], Muc5AC and Muc 6 in gastric tissue [99]. In many human carcinomas, the expression profile of mucins is altered; certain mucins are up-regulated, whereas others are down-regulated [100,101].

MUC1 is a transmembrane glycoprotein found in the developing intrahepatic bile ducts in fetal liver [102] but not in the normal adult intrahepatic biliary tract [103, 104]. MUC1 apomucin is proposed as an oncofetal antigen in the intrahepatic biliary tree [102] and its elevated expression is an independent risk factor for poor outcome of patients with ICC [105,106].

In particular Boonla et al. found a significant correlation between high levels of MUC1 and vascular invasion in patients affected by ICC. Whereas high expression of MUC 5AC significantly correlated with neural invasion and advanced ICC stage [107]. The poor prognosis of ICC patients is also due to neural metastasis and mucin $5 \mathrm{AC}$ plays a role in the late stage carcinogenesis. It can be considered to be excellent biomarkers in tumour progression [108].

Also other mucins can be useful in the diagnosis of intrahepatic cholangiocarcinoma. Zhao et al. noted that immunoprofile of mucins can help in the differentiation between ICC and metastatic colorectal adenocarcinoma to liver. The immunophenotype of MUC2/MUC6-/CK7+/CK20- indicates the diagnosis of intrahepatic cholangiocarcinoma, while MUC2+/MUC6+/ CK7-/CK20+ suggests the possibility of metastatic colorectal adenocarcinoma [109].

\subsection{Metalloproteinase-7 (MMP-7)}

Tumour cells invade the basement membrane secreting enzymes that digest the extracellular matrix pro- teins. These enzymes are metalloproteinase (MMPs). The last are zinc-dependent endopeptidase and are involved in the turnover and degradation of the extracellular matrix (ECM) components and basement membranes [110]. Unlike most MMPs are expressed by stromal cells, MMP-7 is principally expressed by epithelial cells [111]. The serum MMP-7 level is elevated in many cancers that originate from epithelial cells such as colorectal, ovarian and renal cancer [112, 113]. Many studies have demonstrated cholangiocarcinoma specimens frequently express MMP-7 [114] and the serum MMP-7 level is higher in cholanciocarcinoma patients than benign biliary tract disease patients. MMp-7 can be useful for the clinical diagnosis of cholangiocarcinoma especially in patients with obstructive jaundice. Moreover it is considered a indicator of poor postoperative prognosis in cholangiocarcinoma patients [114] but further studies are need to confirm this possible role of MMP-7.

\subsection{Serotonin}

Serotonin, or 5-hydroxytryptamine (5-HT), is a neuroendocrine hormone, synthesized in serotonergic neurons in the central nervous system [115] and in enterochromaffin cells throughout the gastrointestinal tract [116]. Serotonin may have a role in the G1/S transition check point through 5-HT2 receptors. In the liver, inhibition of the 5-HT2 receptors arrested liver regeneration only when administered late $(16 \mathrm{~h})$ after partial hepatectomy [117].

Studies have shown that liver regeneration after partial hepatectomy was completely dependent upon platelet-derived serotonin, as a mouse model of thrombocytopenia inhibited normal liver regeneration in a 5HT2 receptor-dependent manner [118].

In particular serotonin is involved in the pathogenesis of certain clinical features of cholangiopathies, fatigue, and pruritus $[119,120]$. In animal models of chronic cholestasis, this may be due to an enhanced release of serotonin in the central nervous system and its interactions with subtype 1 serotonin receptors [120]. Cholangiocytes synthesize and secrete serotonin, which is increased in proliferating rat cholangiocytes after bile duct ligation (BDL) [121].

Further Alpini et al., found that the expression of the enzyme responsible for serotonin synthesis in the gastrointestinal tract, TPH1, is upregulated in cholangiocarcinoma; They showed that the enzyme responsible for serotonin degradation, MAO A, is markedly decreased in cholangiocarcinoma samples and that this 
Table 1

Sensitivity and specificity of markers

\begin{tabular}{lcc}
\hline \multicolumn{3}{c}{ Cholangiocarcinoma } \\
\hline Markers & Sensitivity & Specificity \\
\hline CA 19-9 & $\uparrow \uparrow \uparrow$ & $\uparrow \uparrow \uparrow$ \\
CEA & $\uparrow^{*}$ & $\uparrow *$ \\
CA 125 & $\uparrow$ & $\uparrow$ \\
SERUM TOTAL SIALIC ACID & $\uparrow^{*}$ & $\uparrow^{*}$ \\
CRP & * $^{* *}$ & $\uparrow * *$ \\
CYFRA 21-1 & $\uparrow \uparrow$ & $\uparrow \uparrow \uparrow$ \\
TGF $\beta$ & $\uparrow$ & $\uparrow$ \\
CGA & $\uparrow$ & $\uparrow$ \\
TUM2- PK & $\uparrow \uparrow$ & $\uparrow \uparrow$ \\
MUCINS & $\uparrow \uparrow$ & $\uparrow \uparrow$ \\
MMP-7 & $\uparrow \uparrow$ & $\uparrow \uparrow \uparrow$ \\
SEROTONIN & $\uparrow$ & $\uparrow$ \\
\hline
\end{tabular}

${ }^{*}$ Elevated in association with others markers; ${ }^{* *}$ It is a independent prognostic indicator in patients with cholangiocarcinoma.

results in an overall increase in serotonin secretion from cholangiocarcinoma cells and in the bile from cholangiocarcinoma patients [122].

This study suggests that the dysregulation of serotonin metabolism may be a key feature associated with the progression of cholangiocarcinoma and modulation of this metabolic pathway may result in the development of an effective adjunct therapy to treat this deadly disease.

\section{Summary and perspective}

Cholangiocarcinoma is an aggressive malignancy that often invades and metastasises to other organs resulting in a poor prognosis [123]. CCA is difficult to diagnose, even with the aid of modern ultrasonographic scanning and computerized tomography.

The tumor markers could represent an help in clinical practice. The marker most studied is CA 19-9 and CEA. The concentrations of CA 19-9 could raise in patients with benign inflammantion as well as malignant disease [124-127]. The sensitivity and specificity could be raised by combining CA 19-9 and CEA.

Only a marker in diagnosis of CCA is not enough and the joint of multiple markers in necessary. The increase of serum levels of CEA alone is not diagnostic but this marker is useful in association with others raising their sensitivity and specificity. Also the use of different components of the same family is important, helping in the differentiation between biliary and/or hepatic neoplasms.

Despite the published data, till today we are still far from the identification of the specific biomarker for detection of CCA (Table 1). Further studies should fo- cus on disease monitoring, therapy evaluation and the combination with new and old biomarkers of CCA.

\section{References}

[1] G.L. Tyson, H.B. El-Serag. Risk factors for cholangiocarcinoma. Hepatology 54 (2011), 173-184.

[2] B.R. Blechacz, G.J. Gores. Cholangiocarcinoma. Clin Liver Dis 12 (2008), 131-150.

[3] R.A. Standish, E. Cholongitas, A. Dhillon, A.K. Burroughs, A.P. Dhillon. An appraisal of the histopathological assessment of liver fibrosis. Gut 55 (2006), 569-78.

[4] O. Nehls, M. Gregor, B. Klump. Serum and bile markers for cholangiocarcinoma. Semin Liver Dis 24 (2004), 139-154.

[5] S.G. Lee, G.W. Song, S. Hwang, T.Y. Ha, D.B. Moon, et al. Surgical treatment of hilar cholangiocarcinoma in the new era: the Asan experience. J Hepatobiliary Pancreat Sci 17 (2010), 476-489.

[6] S. Hirano, S. Kondo, E. Tanaka, T. Shichinohe, T. Tsuchikawa, et al. Outcome of surgical treatment of hilar cholangiocarcinoma: A special reference to postoperative morbidity and mortality. J Hepatobiliary Pancreat Sci 17 (2010), 455-462.

[7] V. Cardinale, G. Carpino, L. Reid, E. Gaudio, D. Alvaro. Multiple cells of origin in cholangiocarcinoma underlie biological, epidemiological and clinical heterogeneity. World J Gastrointest Oncol 4 (2012), 94-102.

[8] M. Yamamoto, S. Ariizumi. Surgical outcomes of intrahepatic cholangiocarcinoma. Surg Today 41 (2011) 896-902.

[9] O. Farges, D. Fuks. Clinical presentation and management of intrahepatic cholangiocarcinoma. Gastroenterol Clin Biol 34 (2010), 191-199.

[10] S. Yamasaki. Intrahepatic cholangiocarcinoma: macroscopic type and stage classification. J Hepatobiliary Pancreat Surg 10 (2003), 288-291.

[11] H. Nathan, et al. A proposed staging system for intrahepatic cholangiocarcinoma. Ann Surg Oncol 16 (2009), 14-22.

[12] A. Sasaki, et al. Intrahepatic peripheral cholangiocarcinoma: Mode of spread and choice of surgical treatment. Br J Surg 85 (1998), 1206-1209.

[13] B. Blechacz, G.J. Gores. Positron emission tomography scan for a hepatic mass. Hepatology 52 (2010), 2186-2191.

[14] V. Vilgrain, et al. Intrahepatic cholangiocarcinoma: MRI and pathologic correlation in 14 patients. J Comput Assist Tomogr 21 (1997), 59-65.

[15] C.U. Corvera, et al. 18F-fluorodeoxyglucose positron emission tomography influences management decisions in patients with biliary cancer. J Am Coll Surg 206 (2008), 5765.

[16] G. Bertino, A. Ardiri, M. Malaguarnera, G. Malaguarnera, N. Bertino, G.S. Calvagno. Hepatocellualar carcinoma serum markers. Semin Oncol 39 (2012), 410-33.

[17] N. Chalasani, A. Baluyut, A. Ismail, A. Zaman, G. Sood, R. Ghalib, T.M. McCashland, K.R. Reddy, X. Zervos, M.A. Anbari, H. Hoen. Cholangiocarcinoma in patients with primary sclerosing cholangitis: A multicenter case-control study. Hepatology 31 (2000), 7-11.

[18] A.H. Patel, D.M. Harnois, G.G. Klee, N.F. LaRusso, G.J. Gores. The utility of CA 19-9 in the diagnoses of cholangiocarcinoma in patients without primary sclerosing cholangitis. Am J Gastroenterol 95 (2000), 204-7. 
[19] C. Levy, J. Lymp, P. Angulo, G.J. Gores, N. Larusso, K.D. Lindor. The value of serum CA 19-9 in predicting cholangiocarcinomas in patients with primary sclerosing cholangitis. Dig Dis Sci 50 (2005), 1734-40.

[20] S.A. Khan, H.C. Thomas, B.R. Davidson, S.D. TaylorRobinson. Cholangiocarcinoma. Lancet 366 (2005), 13031314.

[21] J.K. Ramage, A. Donaghy, J.M. Farrant, R. Iorns, R. Williams. Serum tumor markers for the diagnosis of cholangiocarcinoma in primary sclerosing cholangitis. Gastroenterology 108 (1995), 865-9.

[22] W.F. Shen, W. Zhong, F. Xu, T. Kan, L. Geng, F. Xie, C.J. Sui, J.M. Yang. Clinicopathological and prognostic analysis of 429 patients with intrahepatic cholangiocarcinoma. World J Gastroenterol 15 (2009), 5976-82.

[23] L.Y. Tao, L. Cai, X.D. He, W. Liu, Q. Qu. Comparison of serum tumor markers for intrahepatic cholangiocarcinoma and hepatocellular carcinoma. Am Surg 76 (2010), 12101213.

[24] H. Koprowski, Z. Steplewski, K. Mitchell, M. Herlyn, D. Herlyn, P. Fubrer. Colorectal carcinoma antigens detected by hybridoma antibodies, Somatic Cell. Genet 5 (1979), 957-971.

[25] C.X. Zheng, W.H. Zhan, J.Z. Zhao, D. Zheng, D.P. Wang, Y.L. He et al. The prognostic value of preoperative serum levels of CEA, CA19-9 and CA72-4 in patients with colorectal cancer, World J. Gastroenterol 7 (2001), 431-434.

[26] Y. Nakanuma, M. Sasaki. Expression of blood group-related antigens in the intrahepatic biliary tree and hepatocytes in normal livers and various hepatobiliary diseases, Hepatology 10 (1988), 174-178

[27] T. Kanai, S. Hirohashi, M.P. Upton, Y. Ino, Y. Shimosato. Expression of Lewis blood group antigens in cancerous and non-cancerous liver, Japan J. Cancer Res 78 (1987), 968976.

[28] F.H. Li, X.Q. Chen, H.Y. Luo, Y.H. Li, F. Wang, M.Z. Qiu, K.Y. Teng, Z.H. Li, R.H. Xu. Prognosis of 84 intrahepatic cholangiocarcinoma patients]. Ai Zheng 28 (2009), 528-32.

[29] S. Miwa, S. Miyagawa, A. Kobayashi, Y. Akahane, T. Nakata, M. Mihara et al. Predictive factors for intrahepatic cholangiocarcinoma recurrence in the liver following surgery, J. Gastroenterol 41 (2006), 893-900.

[30] C.Y. Chen, S.C. Shiesh, H.C. Tsao, X.Z. Lin. The assessment of biliary CA 125 , CA 19-9 and CEA in diagnosing cholangiocarcinoma - the influence of sampling time and hepatolithiasis, Hepatogastroenterology 49 (2002), 616-20.

[31] B.W. Yin, K.O. Lloyd. Molecular cloning of the CA125 ovarian cancer antigen: Identification as a new mucin. MUC 16. J Biol Chem 276 (2001), 27371-27375.

[32] H. Hardardottir, T.H. $2^{\text {nd }}$ Parmley, J.G. Jr Quirk, M.M. Sanders, F.C. Miller, T.J. O'Brien. Distribution of CA 125 in embryonic tissues and adult derivatives of the fetal periderm. Am J Obset Gynecol 163 (1990), 1925-1931.

[33] H. Kobayashi, H. Ohi, N. Moniwa, H. Shinohara, T. Terao. Characterization of CA125 antigen identified by monoclonal antibodies that recognize different epitopes. Clin Biochem 26 (1993), 391-397.

[34] M. Higashi, N. Yamada, S. Yokoyama, S. Kitamoto, K. Tabata, C. Koriyama, S.K. Batra, S. Yonezawa. Pathobiological implications of MUC16/CA 125 expression in intrahepatic cholangiocarcinoma- Mass forming type. Pathobiology 79 (2012), 101-106.

[35] M. Uccello, G. Malaguarnera, E.M. Pelligra, A. Biondi, F. Basile, M. Motta. Lipoprotein (a) as a potential marker of residual liver function in hepatocellular carcinoma. Indian $\mathbf{J}$ Med Paediatr Oncol 32 (2011), 71-5.

[36] H. Berbeć, A. Paszkowska, B. Siwek, K. Gradziel, M. Cybulski. Total serum sialic acid concentration as a supporting marker of malignancy in ovarian neoplasia. Eur J Gynaecol Oncol 20 (1999), 389-92.

[37] M. Uccello, G. Malaguarnera, M. Vacante, M. Motta. Serum bone sialoprotein levels and bone metastases. J Cancer Res Ther 7 (2011), 115-9.

[38] S. Narayanan. Sialic acid as a tumor marker. Ann Clin Lab Sci 24 (1994), 376-84.

[39] G. Malaguarnera, E. Cataudella, M. Giordano, G. Nunnari, G. Chisari, M. Malaguarnera. Toxic hepatitis in occupational exposure to solvents. World J Gastroenterol 18 (2012), 275666.

[40] S. Wongkham, C. Boonla, S. Kongkham, C. Wongkham, V. Bhudhisawasdi, B. Sripa. Serum total sialic acid in cholangiocarcinoma patients: An ROC curve analysis. Clin Biochem 34 (2001), 537-41.

[41] K. Okada, Y. Shimizu, S. Nambu, K. Higuchi, A. Watanabe. Interleukin-6 functions as an autocrine growth factor in a cholangiocarcinoma cell line. J Gastroenterol Hepatol 9 (1994), 462-7.

[42] J. Park, L. Tadlock, G.J. Gores, T. Patel. Inhibition of interleukine 6-mediated mitogen-activated protein kinase activation attenuates growth of a cholangiocarcinoma cell line. Hepatology 30 (1999), 1128-33.

[43] J.S. Goydos, A.M. Brumfield, E. Frezza, A. Booth, M.T. Lotze, S.E. Carty. Marked elevation of serum interleukin-6 in patients with cholangiocarcinoma: validation of utility as a clinical marker. Ann Surg 227 (1998), 398-404.

[44] T. Gerhardt, S. Milz, M. Schepke, G. Feldmann, M. Wolff, T. Sauerbruch et al. C-reactive protein is a prognostic indicator in patients with perihilar cholangiocarcinoma. World $\mathrm{J}$ Gastroenterol 14 (2006), 5495-500.

[45] M. Uccello, G. Malaguarnera, T. Corriere, A. Biondi, F. Basile, M. Malaguarnera. Risk of hepatocellular carcinoma in workers exposed to chemicals. Hepat Mon 12 (2012), e5943.

[46] T. Saisho, T. Okusaka, H. Ueno, C. Morizane, S. Okasada. Prognostic factors in patients with advanced biliary tract receiving chemotherapy. Hepatogastroenterology 52 (2005), 1654-1658.

[47] R. Moll, W.W. Franke, D.L. Schiller et al. The catalogue oh human cytokeratins: Patterns of expression in normal epithelia, tumors and cultured cells. Cell 31 (1982), 11-24.

[48] R. Moll, D.L. Schiller, W.W. Franke et al. Identification of protein IT of the intestinal cytoskeleton as a novel type I cytokeratin with unusual properties and expression patterns. J Cell Biol 111 (1990), 567-580.

[49] J.M. Bréchot, S. Chevret, J. Nataf, C. Le Gall, J. Frétault, J. Rochemaure et al. Diagnostic and prognostic value of Cyfra 21-1 compared with other tumour markers in patients with non-small cell lung cancer: A prospective study of 116 patients. Eur J Cancer 33 (1997), 385-91.

[50] M. Takada, N. Masuda, E. Matsuura, Y. Kusunoki, K. Matui, K. Nakagawa et al. Measurement of cytokeratin 19 fragments as a marker of lung cancer by CYFRA 21-1 enzyme immunoassay. Br J Cancer 71 (1995), 160-5.

[51] T. Uenishi, S. Kubo, T. Yamamoto, T. Shuto, M. Ogawa, H. Tanaka et al. Cytokeratin 19 expression in hepatocellular carcinoma predicts early postoperative recurrence, Cancer Sci. 94 (2003), 851-7.

[52] J.L. Pujol, O. Molinier, W. Ebert, J.P. Daurès, F. Barlesi, 
G. Buccheri et al. CYFRA 21-1 is a prognostic determinant in non-small-cell lung cancer: Results of a meta-analysis in 2063 patients. Br J Cancer 90 (2004), 2097-105.

[53] I. Doweck, M. Barak, N. Uri, E. Greenberg. The prognostic value of the tumour marker Cyfra 21-1 in carcinoma of head and neck and its role in early detection of recurrent disease. Br J Cancer 83 (2000), 1696-701.

[54] B. Nakata, T. Takashima, Y. Ogawa, T. Ishikawa, K. Hirakawa. Serum CYFRA 21-1 (cytokeratin-19 fragments) is a useful tumour marker for detecting disease relapse and assessing treatment efficacy in breast cancer. Br J Cancer 31 (2004), 873-8.

[55] Y. Kawarada, R. Mizumoto. Cholangiocellular carcinoma of the liver. Am J Surg 147 (1984), 354-9.

[56] Y. Kawarada, R. Mizumoto. Diagnosis and treatment of cholangiocellular carcinoma of the liver. Hepatogastroenterology 37 (1990), 176-81.

[57] N. Yamanaka, E. Okamoto, T. Ando et al. Clinicopathologic spectrum of resected extraductal mass-forming intrahepatic cholangiocarcinoma. Cancer 76 (1995), 2449-56.

[58] K.M. Chu, E.C. Lai, S. Al-Hadeedi, et al. Intrahepatic cholangiocarcinoma. World J Surg 21 (1997), 301-6.

[59] H.J. Kim, S.S. YunN, K.H. Jung et al. Intrahepatic cholangiocarcinoma in Korea. J Hep Bil Pancr Surg 6 (1999), 1428.

[60] T. Uenishi, K. Hirohashi, S. Kubo, et al. Clinicopathologic factors predicting outcome after resection of mass-forming intrahepatic cholangiocarcinoma. Br J Surg 88 (2001), 96974.

[61] T. Uenishi et al. Cytokeratin-19 fragments in serum (CYFRA 21-1) as a marker in primary liver cancer. Br J Cancer. 88 (2003), 1894-1899.

[62] T. Uenishi et al. Serum cytokeratin 19 fragment (CYFRA211) as a prognostic factor in intrahepatic cholangiocarcinoma. Ann Surg Oncol 15 (2008), 583-589.

[63] P. Van Eyken, V.J. Desmet. Cytokeratins and the liver, Liver 13 (1993), 113-122.

[64] A. Sanchez-Capelo, Dual role for TGF-beta1 in apoptosis. Cytokine Growth Factor Rev 16 (2005), 15-34.

[65] N. Fausto, J.E. Mead, P.A. Gruppuso, L. Brown. TGF-beta in liver development, regeneration and carcinogenesis. Ann N Y Acad Sci 593 (1991), 231-242.

[66] G. Malaguarnera, M. Giordano, I. Paladina, M. Berretta, A. Cappellani, M. Malaguarnera. Serum markers of hepatocellular carcinoma. Dig Dis Sci 55 (2010), 2744-55.

[67] Y. Yata, P. Gotwals, V. Koteliansky, D.C. Rockey, Dosedependent inhibition of hepatic fibrosis in mice by a TGFbeta soluble receptor: Implications for antifibrotic therapy. Hepatology 35 (2002), 1022-1030.

[68] C.B. Thompson. Apoptosis in the pathogenesis and treatment of disease. Science 267 (1995), 1456-1462.

[69] L.A. Saperstein, R.L. Jirtle, M. Farouk, H.J. Thompson, K.S. Chung, W.C. Meyers. Transforming growth factor-beta 1 and mannose 6-phosphate/insulin-like growth factor-II receptor expression during intrahepatic bile duct hyperplasia and biliary fibrosis in the rat. Hepatology 19 (1994), 412-417.

[70] S. Takiya, T. Tagaya, K. Takahashi, H. Kawashima, M. Kamiya, Y. Fukuzawa, S. Kobayashi, A. Fukatsu, K. Katoh, S. Kakumu. Role of transforming growth factor beta 1 on hepatic regeneration and apoptosis in liver diseases. J Clin Pathol 48 (1995), 1093-1097.

[71] Y. Zen, K. Harada, M. Sasaki, T. Chen, M. Chen, T. Yeh et al. Intrahepatic cholangiocarcinoma escapes from growth in- hibitory effect of transforming growth factor-beta1 by overexpression of cyclin D1. Lab Invest 85 (2005), 572-581.

[72] S. Yokomuro, H. Tsuji, J.G. 3rd Lunz, T. Sakamoto, T. Ezure, N. Murase et al. Growth control of human biliary epithelial cells by interleukin 6 , hepatocyte growth factor, transforming growth factor beta1, and activin A: Comparison of a cholangiocarcinoma cell line with primary cultures of nonneoplastic biliary epithelial cells. Hepatology 32 (2000), 26-35.

[73] T. Shimizu, S. Yokomuro, Y. Mizuguchi, Y. Kawahigashi, Y. Arima, N. Taniai et al. Effect of transforming growth factor$\beta_{1}$ on human intrahepatic cholangiocarcinoma cell growth. World J Gastroenterol 12 (2006), 6316-24

[74] L. Malaguarnera, E. Cristaldi, M. Malaguarnera. The role of immunity in elderly cancer. Crit Rev Oncol Hematol 74 (2010), 40-60.

[75] Y. Sato, K. Harada, K. Itatsu, H. Ikeda, Y. Kakuda, S. Shimomura, X. Shan Ren, N. Yoneda, M. Sasaki, Y. Nakanuma. Epithelial-mesenchymal transition induced by transforming growth factor-\{beta\}1/Snail activation aggravates invasive growth of cholangiocarcinoma. Am J Pathol 177 (2010), $141-52$.

[76] L.J. Deftos. Chromogranin A: its role in endocrine function and as an endocrine and neuroendocrine tumor marker. Endocr Rev 12 (1991), 181-7.

[77] A. Spadaro, A. Ajello, C. Morace, A. Zirilli, G. D'Arrigo, C. Luigiano et al. Serum chromogranin-A in hepatocellular carcinoma: diagnostic utility and limits. World J Gastroenterol 11 (2005), 1987-90.

[78] M. Malaguarnera, M. Vacante, R. Fichera, A. Cappellani, E. Cristaldi, M. Motta. Chromogranin A serum levels as a marker of progression in hepatocellular carcinoma (HCC) of elderly patients. Arch Gerontol Geriatr 2009.

[79] M.C. Zatelli, M. Torta, A. Leon, M.R. Ambrosio, M. Gion, P. Tomassetti et al. Chromogranin as a marker of neuroendocrine neoplasia: An Italian Multicenter study. Endocr Relat Cancer 14 (2007), 473-82.

[80] Y. Nakanuma. A novel approach to biliary tract pathology based on similarities to pancreatic counterparts: is the biliary tract an incomplete pancreas? Pathol Int 60 (2010), 419-429.

[81] Y. Nakanuma, M. Sasaki, Y. Sato, X. Ren, H. Ikeda, K. Harada. Multistep carcinogenesis of perihilar cholangiocarcinoma arising in the intrahepatic large bile ducts. World $\mathrm{J}$ Hepatol 1 (2009), 35-42.

[82] Y. Nakanuma, Y. Sato, K. Harada, M. Sasaki, J. Xu, H. Ikeda. Pathological classification of intrahepatic cholangiocarcinoma based on a new concept World J Hepatol 2 (2010), 419-427.

[83] L.A. Erickson, R.V. Lloyd. Practical markers used in the diagnosis of endocrine tumors. Adv Anat Pathol 11 (2004), 175-89.

[84] G.M. Oremek, S. Teigelkamp, W. Kramer, E. Eigenbrodt, K.H. Usadel. The pyruvate kinase isoenzyme tumor M2 (Tu M2-PK) as a tumor marker for renal carcinoma. Anticancer Res 19 (1999), 2599-601.

[85] P.D. Hardt, B.K. Ngoumou, J. Rupp, H. Schnell-Kretschmer, H.U. Kloer. Tumor M2-pyruvate kinase: A promising tumor marker in the diagnosis of gastro-intestinal cancer. Anticancer Res 20 (2000), 4965-8.

[86] G. Schulze, The tumor marker tumor M2-PK: An application in the diagnosis of gastrointestinal cancer. Anticancer Res 20 (2000), 4961-4.

[87] J. Schneider, H. Morr, H.G. Velcovsky, G. Weisse, E. Eigenbrodt. Quantitative detection of tumor M2-pyruvate kinase 
in plasma of patients with lung cancer in comparison to other lung diseases. Cancer Detect Prev 24 (2000), 531-5.

[88] E. Eigenbrodt, M. Reinacher, U. Scheefers-Borchel, H. Scheefers, R. Friis. Double role for pyruvate kinase type M2 in the expansion of phosphometabolite pools found in tumor cells. Crit Rev Oncogenesis 3 (1992), 91-115.

[89] M. Malaguarnera, C. Risino, M.P. Gargante, G. Oreste, G. Barone, A.V. Tomasello, M. Costanzo, M.A. Cannizzaro. Decrease of serum carnitine levels in patients with or without gastrointestinal cancer cachexia. World J Gastroenterol 12 (2006), 4541-5.

[90] E. Vinci, E. Rampello, L. Zanoli, G. Oreste, G. Pistone, M. Malaguarnera. Serum carnitine levels in patients with tumoral cachexia. Eur J Intern Med 16 (2005), 419-23.

[91] U. Brinck, E. Eigenbrodt, M. Oehmke, S. Mazurek, G. Fischer. L- and M2- pyruvate kinase expression in renal cell carcinomas and their metastases. Virchows Arch 424 (1994), 177-185.

[92] P. Steinberg, A. Klingelhöffer, A. Schäfer, G. Wüst, G. Weisse, F. Oesch et al. Expression of pyruvate kinase M2 in preneoplastic hepatic foci of $\mathrm{N}$-nitrososmorpholine-treated rats. Virchows Arch 434 (1999), 213-220.

[93] H.R. Christofk, M.G. Vander Heiden, M.H. Harris, A. Ramanathan, R.E. Gerszten, R. Wei et al. The M2 slice isoform of pyruvate kinase is important for cancer metabolism and tumour growth. Nature 452 (2008), 230-233.

[94] E. Eigenbrodt, F. Kallinowski, M. Ott, S. Mazurek, P. Vaupel. Pyruvate kinase and the interaction of amino acid and carbohydrate metabolism in solid tumors. Anticancer Res 18 (1998), 3267-74

[95] Y.G. Li, N. Zhang. Clinical significance of serum tumour M2-PK and CA19-9 detection in the diagnosis of cholangiocarcinoma. Dig Liver Dis 41 (2009), 605-8.

[96] M. Verma. Carcinoma associated mucins molecular biology and clinical application, Cancer Biochem. Biophys 14 (1994), 151-62.

[97] S.J. Gendler, A.P. Spicer. Epithelial mucin genes. Annu Rev Physiol 57 (1995), 607-34.

[98] S.K. Chang, A.F. Dohrman, C.B. Basbaum, S.B. Ho, T. Tsuda, N.W. Toribara et al. Localization of mucin (MUC2 and MUC3) messenger RNA and peptide expression in human normal intestine and colon cancer. Gastroenterology 107 (1994), 28-36.

[99] M.P. Buisine, L. Devisme, V. Maunorv, E. Deschodt, B. Gosselin, M.C. Copin et al. Developmental mucin gene expression in the gastroduodenal tract and accessory digestive glands. I. Stomach. A relationship to gastric carcinoma. J Histochem Cytochem 481 (2000), 657-66.

[100] S.B. HO, G.A. Niehans, C. Lyftogt, P.S. Yan, D.L. Cherwitz, E.T. Gum et al. Heterogeneity of mucin gene expression in normal and neoplastic tissues. Cancer Res 53 (1993), 64151.

[101] V.P. Bhavanandan. Cancer-associated mucins and mucintype glycoproteins. Glycobiology 1 (1991), 493-503.

[102] M. Sasaki, Y. Nakanuma, T. Terada, Y.S. Kim. Biliary epithelial expression of MUC1, MUC2, MUC3 and MUC5/6 apomucins during intrahepatic bile duct development and maturation. An immunohistochemical study. Am J Pathol 147 (1995), 574-579.

[103] M. Sasaki, Y. Nakanuma. Expression of mucin core protein of mammary type in primary liver cancer. Hepatology 20 (1994), 1192-1197.

[104] K. Yamashita, S. Yonezawa, S. Tanaka, H. Shirahama, K. Sakoda, K. Imai, P.X. Xing, I.F. McKenzie, J. Hilkens, Y.S.
Kim. Immunohistochemical study of mucin carbohydrates and core proteins in hepatolithiasis and cholangiocarcinoma. Int J Cancer 55 (1993), 82-91.

[105] M. Sasaki, Y. Nakanuma, Y.S. Kim. Characterization of apomucin expression in intrahepatic cholangiocarcinomas and their precursor lesions: An immunohistochemical study. Hepatology 24 (1996), 1074-1078.

[106] N. Matsumura, M. Yamamoto, A. Aruga, K. Takasaki, M. Nakano. Correlation between expression of MUC1 core protein and outcome after surgery in mass-forming intrahepatic cholangio-carcinoma. Cancer 94 (2002), 1770-1776.

107] C. Boonla, B. Sripa, P. Thuwajit, U. Cha-On, A. Puapairoj, M. Miwa, S. Wongkham. MUC1 and MUC5AC mucin expression in liver fluke-associated intrahepatic cholangiocarcinoma. World J Gastroenterol 11 (2005), 4939-4946.

[108] T.S. Yeh, J.H. Tseng, T.C. Chen, N.J. Liu, C.T. Chiu, Y.Y. Jan et al. Characterization of intrahepatic cholangiocarcinoma of the intraductal growth-type and its precursor lesions. Hepatology 42 (2005), 657-64

[109] S.M. Zhao, X.Z. Zhu, Y. Ji, J. Hou. Expression of mucin glycoproteins and cytokeratins in intrahepatic cholangiocarcinoma. Zhonghua Bing Li Xue Za Zhi 37 (2008), 749-53.

[110] L.J. McCawley, L.M. Matrisian. Matrix metalloproteinases: Multifunctional contributors to tumor progression. Mol Med Today 6 (2000), 149-56.

[111] A.R. Folgueras, A.M. Pendás, L.M. Sánchez, C. López-Otín. Matrix metalloproteinases in cancer: From new functions to improved inhibition strategies. Int J Dev Biol 48 (2004), 411-24.

[112] A. Acar, A. Onan, U. Coskun, A. Uner, U. Bagriacik, F. Atalay et al. Clinical significance of serum MMP-2 and MMP-7 in patients with ovarian cancer. Med Oncol 25 (2008), 27983.

[113] G. Sarkissian, P. Fergelot, P.Y. Lamy, J.J. Patard, S. Culine, P. Jouin et al. Identification of pro-MMP-7 as a serum marker for renal cell carcinoma by use of proteomic analysis. Clin Chem 54 (2008), 574-81.

[114] K. Itatsu, Y. Zen, S. Ohira, A. Ishikawa, Y. Sato, K. Harada et al. Immunohistochemical analysis of the progression of flat and papillary preneoplastic lesions in intrahepatic cholangiocarcinogenesis in hepatolithiasis. Liver Int 27 (2007), 117484.

[115] M. Diksic, S.N. Young. Study of the brain serotonergic system with labeled alpha-methyl-L-tryptophan. J Neurochem 78 (2001), 1185-1200.

[116] M.M. Costedio, N. Hyman, G.M. Mawe. Serotonin and its role in colonic function and in gastrointestinal disorders. Dis Colon Rectum 50 (2007), 376-388.

[117] G.K. Papadimas, K.N. Tzirogiannis, G.I. Panoutsopoulos, M.D. Demonakou, S.D. Skaltsas, R.I. Hereti et al. Effect of serotonin receptor 2 blockage on liver regeneration after partial hepatectomy in the rat liver, Liver Int 26 (2006), 352361.

[118] R. Acquaviva, L. Iauk, V. Sorrenti, R. Lanteri, R. Santangelo, A. Licata, F. Licata, A. Vanella, M. Malaguarnera, S. Ragusa, C. Di Giacomo. Oxidative profile in patients with colon cancer: Effects of Ruta chalepensis L. Eur Rev Med Pharmacol Sci 15 (2011), 181-91.

[119] L. Proietti, R. Fantauzzo, B. Longo, M. Malaguarnera, M. Trizzino, D. Duscio. Viral hepatitis B among the health care workers. Experience at a health facility in Eastern Sicily. Recenti Prog Med 95 (2004), 196-9.

[120] M.G. Swain, M. Maric. Improvement in cholestasisassociated fatigue with a serotonin receptor agonist using 
a novel rat model of fatigue assessment. Hepatology 25 (1997), 291-4.

[121] M. Marzioni, S. Glaser, H. Francis et al. Autocrine/ paracrine regulation of the growth of the biliarytree by the neuroendocrine hormone serotonin. Gastroenterology 128 (2005), 121-37.

[122] G. Alpini, P. Invernizzi, E. Gaudio, J. Venter, S. Kopriva, F. Bernuzzi, P. Onori, A. Franchitto, M. Coufal, G. Frampton, D. Alvaro, S.P. Lee, M. Marzioni, A. Benedetti, S. DeMorrow. Serotonin metabolism is dysregulated in cholangiocarcinoma, which has implications for tumor growth. Cancer Res 68 (2008), 9184-93.

[123] K. Shirabe, M. Shimada, N. Harimoto, K. Sugimachi, Y. Yamashita, E. Tsujita et al. Intrahepatic cholangiocarcinoma: Its mode of spreading and therapeutic modalities. Surgery 131 (2002), S159-64
[124] H. Minato, Y. Nakanuma, T. Terada. Expression of blood group related antigens in cholangiocarcinoma in relation to non neoplastic bile ducts. Histopathology 28 (1996), 411419.

[125] E. Bjornsson, A. Kilander, R. Olsson. CA 19-9 and CEA are unreliable markers for cholangiocarcinoma in patients with primary scelorising cholangitis. Liver 19 (1999), 501-508.

[126] C.L. Lin, C.S. Changchien, Y.S. Chen. Mirizzi's syndrome with a high CA 19-9 level mimicking cholangiocarcinoma. Am J Gastroenterol 92 (1997), 2309-2310.

[127] Y. Horsmans, A. Laka, B.E. van Beers, C. Descamps, J.F. Gigot, A.P. Geubel. Hepatobiliary cystadenocarcinoma without ovarian stroma and normal CA 19-9 levels. Unusually prolonged evolution. Dig Dis Sci 42 (1997), 1406-1408. 


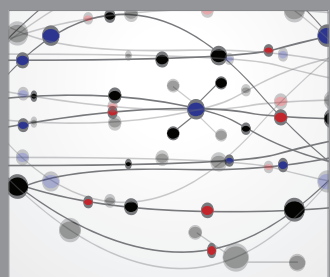

The Scientific World Journal
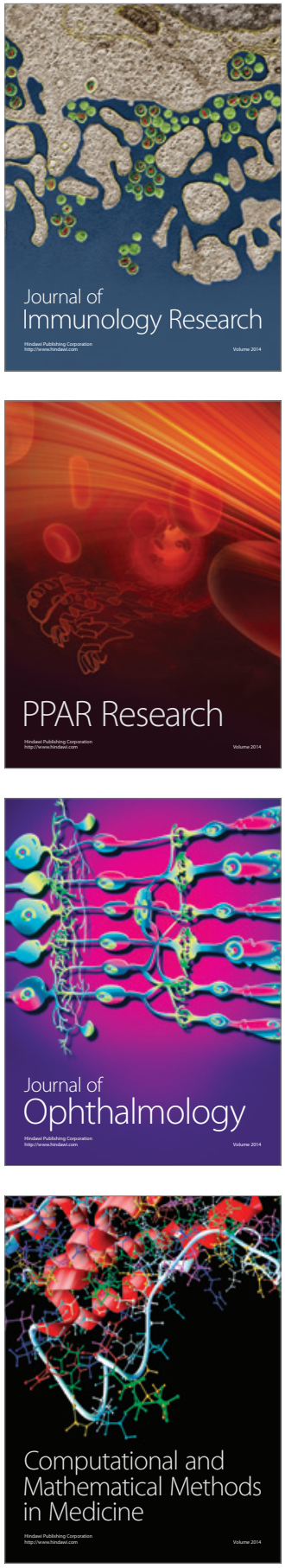

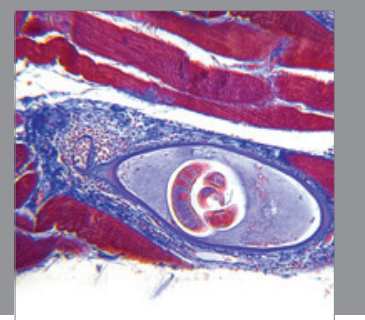

Gastroenterology

Research and Practice
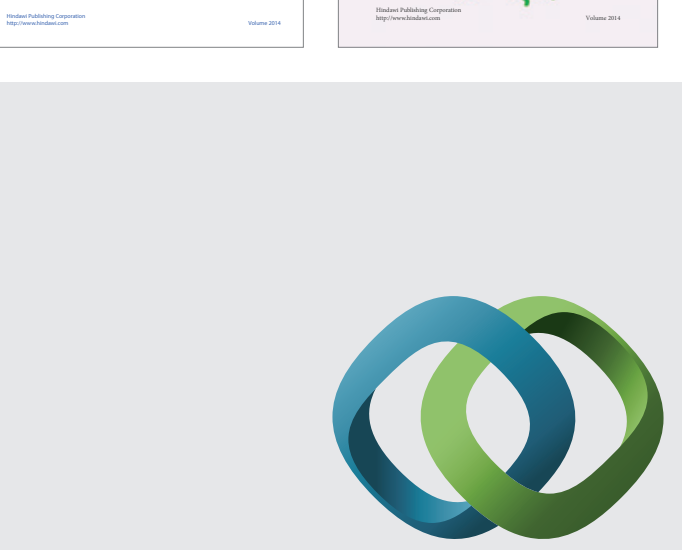

\section{Hindawi}

Submit your manuscripts at

http://www.hindawi.com
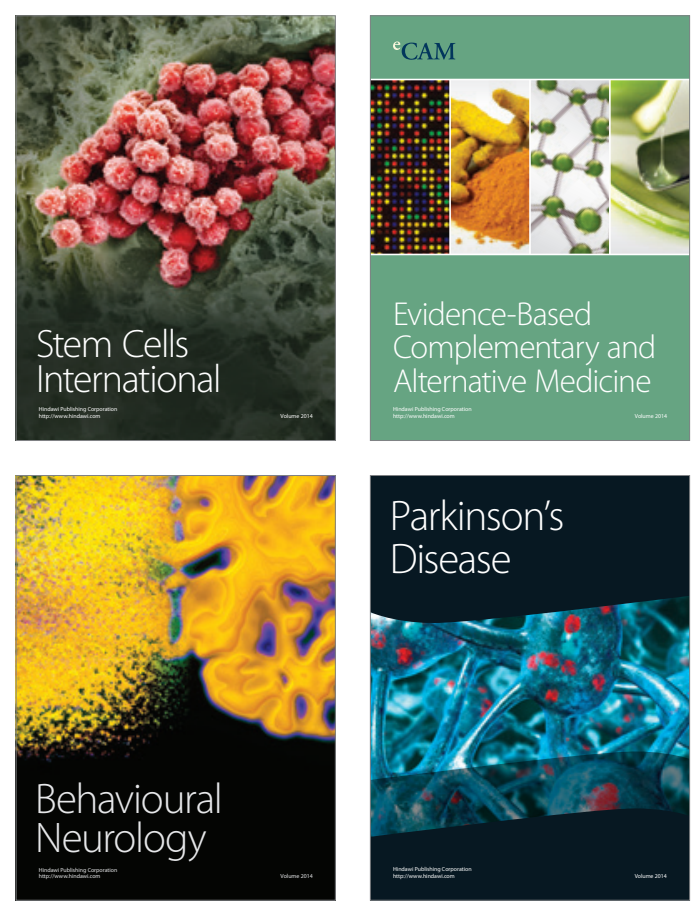

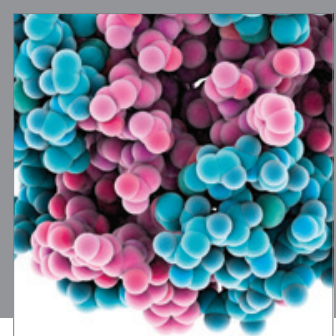

Journal of
Diabetes Research

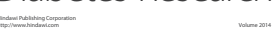

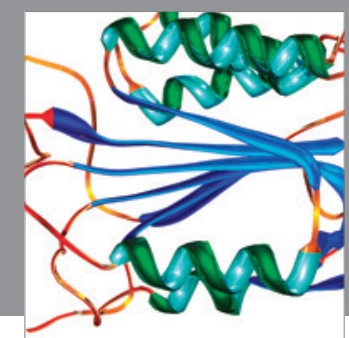

Disease Markers
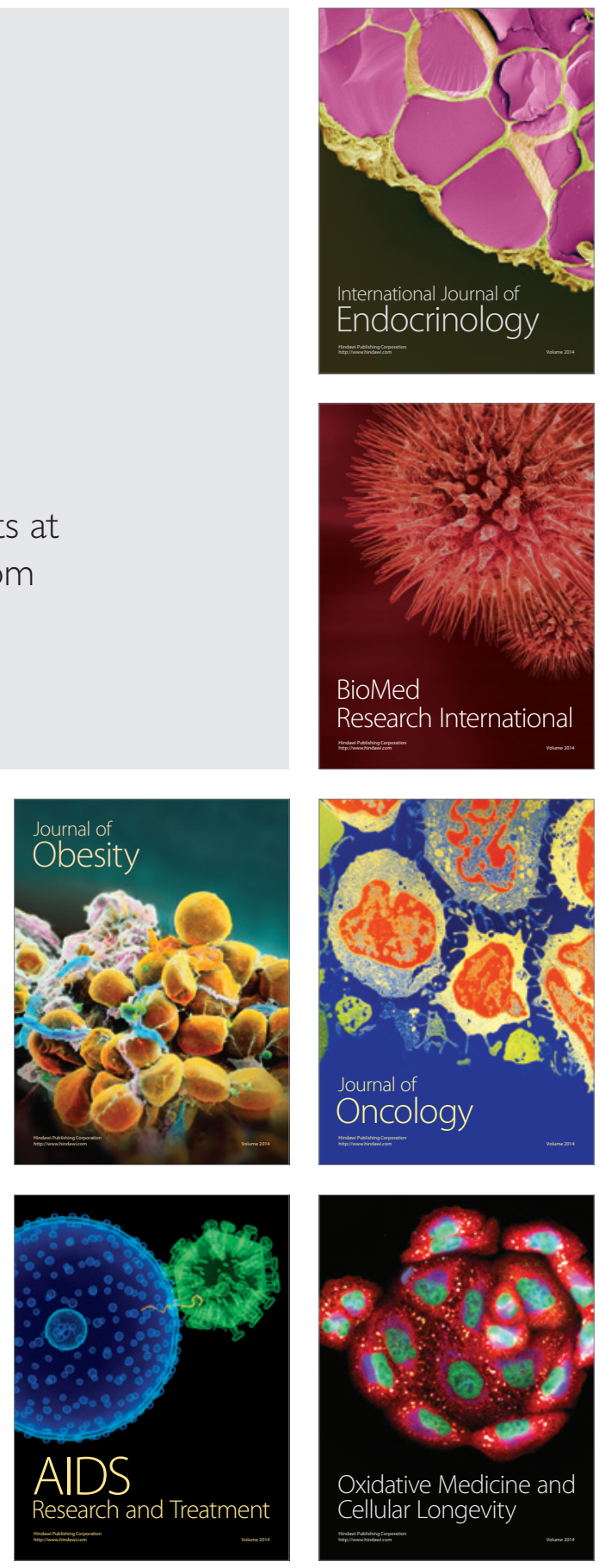